\title{
Prenatal smoking cessation strategies in managed care
}

Dianne C Barker, Carol McPhillips-Tangum

Treatment of nicotine addiction is an important component of any prenatal care plan. For a managed care system, investment in smoking cessation interventions for the pregnant women is cost effective, ${ }^{1}$ resulting in healthier women and infants. In 1997-98, the Robert Wood Johnson Foundation and American Association of Health Plans (AAHP) Addressing Tobacco in Managed Care (ATMC) National Technical Assistance Office conducted a survey of 542 AAHP member plans, achieving a $60 \%$ response rate. Methods and overall results are reported elsewhere. ${ }^{2} \mathrm{~A}$ follow up survey to the ATMC survey will be conducted later in 1999 to measure further the extent and content of existing prenatal smoking cessation programs in managed care. To summarise our knowledge to date regarding tobacco treatment programs for pregnant women, we further analysed the existing ATMC survey, examining differences between those managed care organisations (MCOs) who reported having a special strategy addressing smoking cessation during pregnancy $(n=145)$, and those who did not $(n=173)$.

Plans with a prenatal smoking cessation strategy were more likely to consider smoking cessation in general a high priority $(43 \% v$ $34 \%$ ), cover smoking cessation for all its members $(49 \%$ v 34\%), and have other strategies targeting special populations (that is, myocardial infarction survivors, adolescents, hospitalised patients) in place (40\% $v 7 \%)$. These plans also were more likely to have implemented the Agency for Health Care Policy Research smoking cessation guidelines, ${ }^{3}$ partially or fully, once they were aware of the guidelines (57\% v 33\%), and to have systems in place to identify smokers $(19 \%, v 12 \%)$. (These data were analysed using the $\chi^{2}$ test of association. All of the above comparisons were significant at the $\mathrm{p}<0.05$ level.) Identifying smokers before pregnancy is particularly important, because many pregnant women fail to report their smoking behaviour. ${ }^{4}$
When we examine those 145 MCOs with a prenatal smoking cessation strategy more closely, we see some encouraging signs around the 4A's (ask, advise, assist, arrange). Over two thirds instruct their providers to ask new patients about smoking, and if patients smoke, advise them to quit. However, less than a half instruct providers to counsel patients and provide materials. And the rates drop off considerably-26\% refer patients to more intensive counselling, $22 \%$ arrange follow up, and less than two fifths encourage patients to provide a smoke free environment for their children. And for those plans with a pregnancy strategy who do instruct providers to ask new patients about smoking at first visit, only $37 \%$ include smoking as a vital sign. That is, they ask patients at every visit.

Turning to systems implementation, while nearly three quarters record smoking status in the chart, only $10 \%$ computerise this information. Training is weak $(20 \%)$, and incentives for patients $(23 \%)$ and providers $(12 \%)$ are not widely implemented.

And lastly, of all the plans that implement a pregnancy strategy, only $30 \%$ include a postpartum strategy to help women remain smoke free. Clearly, we have a long way to go to help managed care take advantage of these cost savings.

The authors wish to express their appreciation to Lisa Mahoney, Abby Rosenthal, Danielle Skripak Stoffer, and Linda Schuessler for making this analysis possible.

1 Marks JS, Koplan JP, Hogue CJR, et al. A cost-benefit/costeffectiveness analysis of smoking cessation for pregnant women. Am f Prev Med 1990;6:282-9.

2 McPhillips-Tangum C. Results from the first annual survey on Addressing Tobacco in Managed Care. Tobacco Control 1998;7(suppl):11-13

3 Fiore MC, Bailey WC, Cohen SJ, et al. Smoking cessation. Clinical Practice Guideline No 18. Rockville, Maryland: US Department of Health and Human Services, Public Health Service, Agency for Health Care Policy and Research, April 1996. (AHCPR Publication No 960692.); <http://www.text.nlm.nih.gov/ftrs/tocview>.

4 Mullen PD, Carbonari JP, Tabak ER, et al. Improving disclosure of smoking by pregnant women. Am f Obstet Gynecol 1991;165:409-13. 